\title{
AGÊNCIA DAS MULHERES SANÖMA E A ATIVAÇÃO DE COSMOPOLÍTICAS
}

Sílvia Maria Ferreira Guimarães (1)

Universidade de Brasília. Departamento de Antropologia I Brasília - DF - Brasil

Instituto Nacional de Ciência e Tecnologia Brasil Plural 
RESUMO

Este artigo discute as experiências das mulheres indígenas Sanöma quando acionam uma cosmopolítica (Stengers 2018), quando desaceleram a construção de um mundo comum, englobante, e articulam mundos múltiplos. Em tais situações, narrativas hegemônicas atreladas a ações estatais no campo da saúde passam a ser questionadas. O movimento dessas mulheres explode caminhos já consolidados para atingir outros fios de convivência, atuando sobre processos colonizadores que pretendem promover uma tensão nas socialidades indígenas, ao fazerem a transferência de práticas ocidentais de cuidado que questionam saberes das mulheres indígenas. Assim, elas resistem na infrapolítica. A agência dessas mulheres tem a potência, em si, de constituir realidades que recusam os significados e a organização social estruturados pelo poder ocidental.

Palavras-chave: mulheres indígenas; etnologia; cosmopolítica; saúde.

\section{SANÖMA WOMEN'S AGENCY AND THE ACTIVATION OF COSMOPOLITICS}

\section{ABSTRACT}

This article discusses the experiences of Sanöma indigenous women when they perform a cosmopolitics (Stengers 2018), when they slow down the construction of a common, encompassing world, and articulate multiple worlds. In such situations, hegemonic narratives linked to state actions in the health field are questioned. The movement of these women explores already consolidated paths to reach other strands of coexistence, acting on colonizing processes that intend to promote a tension in indigenous socialities by transferring western care practices that question the knowledge of indigenous women. Thus, they resist in infrapolitic, the agency of these women has the power in itself to constitute realities that reject the meanings and social organization structured by the Western power.

Keywords: indigenous women; ethnology; cosmopolitics; health

\section{LA AGENCIA DE MUJERES SANÖMA Y LA ACTIVACIÓN DE COSMOPOLÍTICAS}

\section{RESUMEN}

Este artículo tiene como objetivo discutir las experiencias de las mujeres indígenas Sanöma cuando accionan una cosmopolítica (Stengers 2018), cuando reducen la construcción de un mundo común, abarcador, y articulan mundos múltiples. En tales situaciones, las narrativas hegemónicas vinculadas a las acciones estatales en el campo de la salud comienzan a ser cuestionadas. El movimiento de estas mujeres explora caminos ya consolidados para alcanzar otros hilos de convivencia, actuando sobre procesos de colonización que pretenden promover una tensión en las sociabilidades indígenas al realizar la transferencia de prácticas de cuidado occidentales que cuestionan los saberes de las mujeres indígenas. Por lo tanto, ellas resisten en la infra política. Su agencia tiene el poder en sí mismo de constituir realidades que rechazan los significados y la organización social estructurados por el poder occidental.

Palabras clave: mujeres indígenas; etnología; cosmopolítica; salud 


\section{INTRODUÇÃO: PONTO DE PARTIDA E REENCONTROS}

A soberania alimentar e o viver bem do povo Sanöma - que compõe um dos quatro subgrupos da família linguística Yanomami (Migliazza 1967, 1972), localizado no norte do estado de Roraima, Brasil - são manejados, especialmente, pelas mulheres, as quais sempre estiveram envolvidas e atuantes na interação com os não indígenas, especialmente com os serviços de saúde em área.

Elas se fazem presentes nas práticas cotidianas da biomedicina, atuando e interagindo com as equipes multidisciplinares: levam as crianças ao posto médico - que se configuram como o maior foco de atenção dos serviços em área -, passam alguns momentos do dia observando a dinâmica do serviço, trocam cestarias e produtos de suas roças com os profissionais de saúde. No entanto, nos últimos anos, elas estão em uma nova frente, atuando como agentes indígenas e conselheiras de saúde. Tais funções passaram a surgir a partir de uma demanda da Secretaria Especial de Saúde Indígena (SESAI), órgão vinculado ao Ministério da Saúde, para ter a participação das mulheres, fato que elas reinventaram. São elas que manejam a vida, nos termos de Overing $(1991,1999,2004)$, que produzem alimentos, que lidam com a alteridade internamente e produzem uma socialidade.

Este artigo pretende refletir sobre como essas mulheres acionam uma cosmopolítica (Stengers 2008), produzem um movimento a partir do qual elas desaceleram os outros e resistem à maneira como as situações são apresentadas. Elas questionam um mundo único, onde todas/os estariam englobadas/os, inquirindo o englobante. A proposição cosmopolítica dessas mulheres não se refere a estar em um cosmos comum ou compartilhado, mas a um devir que articula o desconhecido de mundos múltiplos (Stengers 2008). De acordo com Stengers (2018:447):

O cosmo, tal qual ele figura nesse termo,
cosmopolítico, designa o desconhecido
que constitui esses mundos múltiplos,
divergentes, articulações das quais eles
poderiam se tornar capazes, contra a
tentação de uma paz que se pretenderia
final, ecumênica, no sentido de que
uma transcendência teria o poder de
requerer daquele que é divergente que
se reconheça como uma expressão
apenas particular do que constitui o
ponto de convergência de todos.

As linhas de reflexões que este artigo visa desenvolver surgiram em 2018, quando o Ministério da Saúde, por meio da SESAI, convidoume para atuar junto aos Sanöma diante de casos de tungíase $^{1} \mathrm{e}$ desnutrição que atingiam as crianças

1 De acordo com a biomedicina, "a tungíase é uma parasitose causada por fêmeas grávidas de uma espécie de pulga [bicho do pé], Tunga penetrans, que habita o solo de zonas arenosas. A contaminação ocorre quando o paciente pisa neste solo sem proteção nos seus pés. A fêmea grávida penetra na pele humana com a sua cabeça e libera seus ovos para o exterior" (SBD 2017). Os denominam esta pulga de kolotomo e, de acordo com eles, o casal vive nas casas, escondido, e vez por outra adentra na pele das pessoas e coloca filhotes. As lembranças dos mais velhos são de que 
deste povo. A proposta que se delineou para esta pesquisa foi apresentada pelos Sanöma e tinha como objetivo central discutir a saúde de todos e todas na comunidade, ou melhor, o que significa para eles estar bem ou viver bem e ter soberania alimentar². Desde 2003, eu não havia retornado à comunidade na Terra Indígena e encontrara com os Sanöma somente nas cidades de Boa Vista e Brasília, quando realizavam tratamentos médicos. Nesse momento, discutira com eles sobre processos de hospitalização e sobre como lidavam com os tratamentos na cidade, em outras espacialidades e temporalidades.

Em conversas com técnicos e gestores da saúde, soube que toda a atual mobilização com relação à saúde dos Sanöma ancora-se em uma preocupação com relação à desnutrição infantil, que vinha apresentando dados alarmantes (Pantoja 2012), sendo também decorrente de uma visita feita por uma equipe formada por profissionais da SESAI e da Fundação das Nações Unidas para a Infância (UNICEF), que esteve nas comunidades Sanöma no início de 2018 e ficou impressionada com os casos de tungíase. Profissionais de saúde do $5^{\circ}$ Batalhão do Exército, localizado no território
Sanöma, chegaram a fazer algumas ações com relação à tungíase nesta área, mas relataram o trabalho a partir de uma culpabilização do modo de ser Sanöma, com uma avaliação preconceituosa e também composta por questionamentos com relação aos serviços de saúde realizados no local (Evangelista \& Ricarte 2017).

Fiquei preocupada com a maneira como o problema foi apresentado. A tungíase estava presente entre os Sanöma em 2003 e 2004, quando vivera com eles pela primeira vez, mas era controlada e acontecia com crianças e idosos que tinham alguma fragilidade ou viviam em grupos domésticos que sofreram perdas de pessoas centrais no cuidado. Essa enfermidade aparecia, por exemplo, em casos de crianças criadas por avós que não enxergavam bem, com dificuldades em retirar os bichos de pé e sem apoio de grupos de mulheres próximas para auxiliá-las. Eram poucos casos.

Desse modo, o quadro apresentado pela equipe da SESAI foi de um grupo indígena com índices alarmantes de desnutrição infantil, um dos mais graves do Brasil, e uma epidemia de tungíase atingindo as crianças da comunidade.

os kolotomo se intensificaram com a presença dos não indígena, pois, quando eram crianças, informam que não havia kolotomo em área.

2 Soberania alimentar é um conceito criado no âmbito do movimento dos trabalhadores rurais e se refere à capacidade de as comunidades produzirem seus próprios alimentos. Os Sanöma encontraram neste conceito ressonância com o que praticam em suas vidas e o definiram na língua como Kamatöpö sainöniitö tö awi (nós sabemos fazer e produzir nosso alimento). 
Seguindo as conversas com a equipe de saúde em Brasília, foram-me apresentados dados/relatos que retratavam os Sanöma e seu modo de viver da seguinte maneira: tinham práticas alimentares deficientes; as crianças passavam o dia comendo chibé (beiju desmanchado na água), o que foi confundido com caxiri (bebida fermentada); não tinham roças ou possuíam roças pequenas e precárias, o que coadunava com a ideia da falta de alimentos; a aparência dos dentes (pretos e amarelos) e corpos das crianças (magras, com barrigas protuberantes, com presença de bichos de pé) era de adoecimento; as crianças ficavam sujas; as moradias eram precárias, com chão de terra batida, sendo que o fogo doméstico aparecia como a principal causa para as doenças respiratórias.

A partir desse relato, retornei à terra Sanöma e os reencontrei, em março de 2018. Foi com alegria que me receberam e que os vi novamente: aqueles que eram crianças, agora, tinham filhos e uma família. Fui de casa em casa. Quando recebi informações calorosas, especialmente sobre os mortos, lamentei com eles a falta dos que faleceram e daqueles que não havia conhecido. Recebi a notícia de que um grupo grande dos Sanöma havia mudado para mais ao leste da Terra Indígena
Yanomami, ao longo do rio Uraricoera, dentro do território Yanomami, local onde se concentram muitos garimpeiros e onde há muitos casos de malária. Esse deslocamento é uma novidade e foi motivado pela falta de acesso a cidades e de caça em abundância. Agora, esse grupo conseguiria acessar, de carro, a cidade de Boa Vista e estava próximo a uma nova fonte de alimentos, "peixes grandes". Vale enfatizar que a região onde os Sanöma vivem, denominada de Auaris, tem esse nome devido à presença do rio Auaris, o qual recorta serras que marcam esse território e deságua no rio Uraricoera. Auaris é um rio de pequenas dimensões e conta com pequenos peixes e crustáceos.

Voltando à comunidade de Auaris, em quase todas as famílias havia relatos de crianças falecidas. Por exemplo, o jovem professor deste local - que era uma criança com, aproximadamente, dez anos quando estivera lá, em 2003 - era agora um pai de família que teve dois filhos mortos na primeira infância. Nesses pequenos relatos de acolhida e de contar as novidades, as mortes de crianças pequenas surgiram em quase todas as casas que visitei ${ }^{3}$. Nas últimas décadas, o Brasil tem apresentado diminuição nas taxas de mortalidade infantil

3 Os Sanöma vivem em casas pequenas, espalhadas ao longo do que se conforma uma aldeia. As casas são denominadas de sai a, retangulares, algumas sem revestimento formando paredes, outras têm palhas e madeiras, outras ainda recebem barro. Em cada casa ou conjunto de casas próximas, encontra-se uma família extensa, composta, preferencialmente, pelos pais, avós, filhas e genros. Para se ter uma aldeia, um conjunto de casas, eles identificam-na com o nome de um antepassado, por exemplo, mosonawa töpö. Esse grupo conforma famílias extensas vinculadas patrilinearmente, irmãs e irmãos de um mesmo antepassado. 
(Victora et al. 2011), no entanto, quando analisamos grupos populacionais específicos, especialmente com o recorte de etnia/raça, esses dados revelam altos índices entre povos indígenas (Marinho et al. 2018). Por conseguinte, a mortalidade infantil é um dado grave entre essas etnias e muitos estudos a associam aos casos de baixa estatura ou desnutrição infantil (Orellana et al. 2019). Essa abordagem deve ser cuidadosamente analisada, sendo essa uma das propostas do projeto de pesquisa que desenvolvo com os Sanöma, pois existem múltiplos caminhos explicativos em todo esse processo, como afirma o Inquérito Nacional de Saúde e Nutrição dos Povos Indígenas (Fiocruz 2009) e os próprios Sanöma.

Nas várias conversas que mantive com os Sanöma, eles destacaram o incômodo de serem vistos como famintos, doentes e descuidados com suas crianças. Uma liderança chegou a me falar: "Nagai, a SESAI pode vir aqui e trabalhar, trabalhar e trabalhar e se a gente continuar assim, pequeno, é porque somos assim mesmos". Ao mesmo tempo, havia uma situação delicada de mortalidade infantil. A questão central é por que estavam morrendo.

Esse é o ponto de partida deste artigo e do projeto de pesquisa que está sendo desenvolvido conjuntamente com a Associação Indígena
Sanöma, Ibasali, criada em 2013. Eles querem firmar uma parceria para que possamos discutir a saúde de todos, mas, especialmente, para discutir a soberania alimentar e o viver bem do povo Sanöma (Kamatöpö sainöniitö tö awi, toita apii kuowi). A proposta é que os Sanöma mantenham, por meio desta pesquisa, um diálogo com a SESAI, e proporcionem mudanças no que concerne às intervenções no campo da saúde propostas pelas instituições governamentais. Este artigo se refere, portanto, a uma pesquisa, ora iniciada, que apresenta problemas etnografados por mim sobre a forma como políticas de saúde e suas intervenções afetam a vida dos Sanöma.

Dessa forma, este artigo é resultado de uma pesquisa estruturada em uma "antropologia do presente", a qual diz respeito ao desafio apresentado por Albert (2014) sobre uma "antropologia engajada", onde estão associadas a "participação observante" e a "solidariedade crítica”. Os caminhos do estudo passam, assim, a ser desenhados por várias mãos e trilhados por vários pés.

\subsection{SOBRE OS SANÖMA E OS CORPOS GENDERIZADOS}

Os Sanöma fazem parte da família linguística Yanomami (Yanomae, Yanõmami, Sanöma e Ninam). No Brasil, os Yanomami são, 
aproximadamente, 27.000 pessoas (SESAI 2019; ISA 2019). Na Venezuela, eram 11.341, em 2011, de acordo com o ISA (2019). Os Sanöma somam, aproximadamente, 3.000 pessoas. A Terra Indígena Yanomami é de 9.664 .974 hectares $\left(96.659 \mathrm{~km}^{2}\right)$, tendo sido homologada pelo governo brasileiro em 1992. Os Yanomami dividem seu território com os Yekuana (povo falante de uma língua caribe), vizinhos dos Sanöma. O polo-base de Auaris é o mais populoso do Distrito Sanitário Especial Indígena (DSEI) Yanomami, contando com 28 aldeias Sanöma e 3.000 pessoas.

Os Sanöma vivem em famílias extensas, marcadas pela uxorilocalidade, ou seja, a mãe e o pai tentam manter suas filhas próximas e agregam, assim, seus genros, que são escolhidos entre primos cruzados. Seguem a patrilinearidade na formação dos grupos e na denominação destes (Ramos 1990). Por meio da uxorilocalidade, uma rede de mulheres se forma e é central no desenvolvimento do cuidado, na produção de alimentos e no cultivo nas roças. A jovem sozinha em meio aos afins sofre grandes desafios quando a uxorilocalidade não acontece. Tudo depende da força política de seu pai e sua mãe para ter as filhas próximas e atrair os genros.

Os dias que passei em área foram marcados pela discussão sobre o problema da tungíase. Fizemos uma grande reunião, na qual estiveram presentes os denominados tuxauas, conselheiros e conselheiras de saúde, agentes indígenas de saúde, professores, entre vários outros Sanöma. Essa reunião contou também com auxílio do batalhão do Exército, pois o comandante estava presente e apresentou seu apoio aos problemas enfrentados pelos Sanöma. Foi um evento marcado pela perspectiva não indígena. Eles, então, reuniram-se, e vários de seus membros discursaram para os setenapi (brancos) ouvirem, dando um tempo para que esses últimos falassem, no caso, eu e o comandante do Exército.

Em outro dia, os Sanöma organizaram um encontro ou uma reunião dos sapuli, os xamãs Sanöma, os quais trataram de temas que tocam a dinâmica da comunidade, juntamente com as mulheres e os homens que não detêm essa qualidade xamânica e observam as interações dos xamãs com seus seres auxiliares, conversando ou interagindo com os xamãs ao longo dessa reunião. Os sapuli contam com o apoio dos seres auxiliares, criaturas invisíveis para os não iniciados, os quais os auxiliam em procedimentos de cura e trazem notícias de várias dimensões do cosmo. Essa é uma das grandes reuniões políticas dos Sanöma, momento do qual fui convidada a participar, a única não indígena presente. Decidiram sobre cerimônias funerárias, convites a grupos vizinhos para participarem desses rituais, organização das caçadas e plantações de roças de bananas, além 
de debaterem sobre as atividades dos brancos na comunidade e trazerem notícias sobre grupos de indígenas vizinhos e a presença de animais de caça nas redondezas.

Apesar da contínua e intensa presença de missionários da Missão Evangélica para a Amazônia (MEWA) na terra Yanomami desde 1970, a potência xamânica, um dos pilares da vida social Sanöma (Taylor 1996), continua dinâmica, distante dos olhares dos não indígenas. Essa reunião presenciada por mim aconteceu em uma casa mais distante de onde se encontravam os não indígenas. O trabalho que desenvolvi anteriormente com os Sanöma aconteceu com os sapuli, e foi marcado pelo diálogo e convivência com os anciãos da comunidade; estava envolvida com esses homens e suas práticas xamânicas (Guimarães 2005). As conversas que tive com as mulheres se referiam mais à fabricação dos corpos e das pessoas, em uma complementaridade às conversas com os sapuli. Reconheço aqui uma fragilidade desse primeiro campo, que se amplifica neste segundo momento: no primeiro encontro, eu não havia ainda compreendido em profundidade a agência feminina, nos termos de Overing (1999) e McCallum (2001), na produção da vida social Sanöma. Agora, no entanto, senti que era sobre elas que recaíam os problemas apresentados pela SESAI. Quando enfatizavam a desnutrição infantil, a tungíase e o descuido com as crianças, estavam apontando e acusando as mulheres e sua agência feminina.

Eram as mulheres Sanöma que cuidavam das crianças pequenas; eram elas as donas das roças, juntamente com os homens com quem eram casadas; donas das casas; que diversificavam a alimentação; e eram elas que dominavam as práticas de preparo dos alimentos. Esses eram os lóci dos problemas que a SESAI desenhava. Diante desse cenário, os Sanöma analisaram como importante discutir com os brancos sobre como se efetiva sua soberania alimentar; como se estrutura o sistema agrícola Sanöma, mantido pelas mulheres; e como os dados epidemiológicos da SESAI retratam seu quadro de saúde.

Mais do que isso, a agência feminina surgia como uma potência na arena interétnica, tendo em vista que essa sempre ficou submersa no diálogo interétnico diante da incapacidade dos brancos de percebê-la e de somente enfatizarem a presença dos homens como intermediadores e lideranças (Benites 2018; Veron 2018). Agora, todavia, elas se colocavam na linha de frente, propositalmente, diante dos não indígenas.

Para compreender essa dinâmica da vida das mulheres Sanöma, cabe tratar da imposição de gênero ocidental em seu coletivo, onde uma relação de poder hierárquica e que subordina 
mulheres a homens está presente, forçando o apagamento de determinadas dimensões da vida social. Conforme afirma Overing (1986), facilmente nossas representações (ocidentalizadas) de opressão, dominação e desigualdade formatam as descrições de gênero em outros contextos. Não estou afirmando que não há concepções de gênero entre os Sanöma. Pelo contrário, os corpos são construídos de maneira genderizada, o problema está em impor percepções de gênero hegemônicas, ocidentais, que se fazem em configurações de relações de poder desiguais, com subordinação de um gênero a outro, como afirma Segato (2012), ao discutir a colonialidade de gênero. $\mathrm{O}$ mundo ocidental e suas instâncias estatais adentram os territórios das comunidades, desorganizando o "tecido social", e uma das primeiras frentes é a imposição de gênero ocidental, ancorada em uma forma de organização social baseada, especialmente, neste âmbito, onde relações de poder hierárquicas e de dominação-subordinação situam os homens como detentores de poder e da esfera pública na negociação da vida social, e as mulheres figuram como meras coadjuvantes, subordinadas. A imposição dessa masculinidade desarticula a vida social e a violência do colonizador se instaura. Lugones (2014) afirma que, nas interações íntimas e da vida cotidiana, há resistência a essa diferenciação social ou dicotomia hierarquizada ocidental. Essa autora afirma que, no "lócus fraturado" da diferença colonial, essas categorias de gênero impostas sofrem resistência na ruptura provocada pela imposição, quando são enfatizados os entes relacionais. No caso das mulheres Sanöma, elas se movimentam na ferida imposta, e a realidade genderizada Sanöma passa a se operacionalizar enganando o colonizador, conforme veremos mais adiante.

Quando me refiro à imposição de gênero ocidental entre os Sanöma, observo esta situação nas relações mantidas entre instâncias governamentais, entre outras, da sociedade nacional e esse povo, que se concretiza na não escuta das mulheres Sanöma, na não participação delas nas decisões com os brancos, no fato de as agências governamentais nunca terem se interessado pelas suas narrativas; nunca terem escutado este público, especialmente no campo da saúde; por questionarem a forma como produzem o alimento e cuidam de seus filhos. O diálogo fomentado pelo contexto interétnico se dá entre homens (brancos e indígenas), impondo masculinidades associadas ao domínio público/ político. Tal diálogo se dá na exclusão dessas mulheres, que compõem a política no "multiverso" Sanöma, esse último entendido aqui nos termos de Viveiros de Castro (2012:158), inspirado em William James, como "uma multiplicidade de províncias e agências intersecantes”. Essas 
hierarquias, que subordinam e criam relações de subjugação entre gêneros, onde um decide sobre a vida do outro, não estão presentes no multiverso Sanöma. Na arena interétnica, essas mulheres passam a enfatizar o dinamismo da vida cotidiana, onde se dá o manejo da vida, e afrontam aqueles que acharam que estavam imobilizadas, internalizadas, subjugadas e identificadas ao plano doméstico/apolítico.

Ao solicitarem a participação das mulheres como agentes indígenas de saúde e conselheiras de saúde, os agentes governamentais ainda permanecem na produção da diferença desigual e hierarquizada entre narrativas masculinas e femininas. Há somente uma agente indígena de saúde, uma jovem mulher que não pode ter filhos e se ressente de sua situação, por isso se mantém distante das arenas de discussão política com os brancos. Faz o seu trabalho no posto como tradutora e atua também na limpeza do espaço. Por outro lado, as conselheiras de saúde são mulheres donas de roças, com filhos, as quais passaram a estar presentes nas reuniões com os brancos, impondo sua fala dura, questionando a atuação dos serviços em área. Sempre estiveram presentes nas reuniões com os sapuli, mantendo o diálogo com os homens; e nas decisões das famílias extensas, sabem sobre suas atividades, decidem sobre elas: quando ir à roça, quando pescar, coletar, quando inserir novos cultivos nas roças, quando produzir beiju, quando fazer artesanato, quando trocar alimentos. Agência, autonomia, confiança e consenso marcam essa vida política, como nos informa Overing (1999).

Na esteira dessa discussão de colonialidade de gênero de Segato (2012) e Lugones (2014), sigo, agora, a trilha argumentativa de Overing (1986) e Belaunde (2001), que enfatizaram ser necessário estarmos atentas a armadilhas como a que lê as obrigações dos homens como status e das mulheres como opressões. Por esse caminho, será possível compreender como as mulheres Sanöma se revelam ativando outras dimensões da vida social.

No contexto dos Airo-Pai, na Amazônia peruana, de acordo com Belaunde (2001), as relações de gênero estão inseridas em uma polaridade dinâmica, ancorada em prestações mútuas de serviços e interdependência simbólica. Overing (1999) analisa como a vida cotidiana dos Piaroa está baseada no princípio da confiança entre agências femininas e masculinas, produzindo uma socialidade e uma moralidade igualitária. É enfatizada a autonomia de um agente moral entre os Piaroa, onde gira a socialidade. Não há espaço para impor uma diferença desigual de gênero, entre homens e mulheres, onde os primeiros detêm o poder coercitivo e as últimas, a informalidade e o íntimo, mas ambos vivem uma moralidade não 
coercitiva da confiança e da autonomia. Nesse contexto, nos processos de fabricação de corpos ou de construção de pessoas, homens e mulheres buscam desenvolver habilidades que permitam o manejo da vida cotidiana e devem se imbuir de agências, feminina e masculina. Overing \& Passes (2000) afirmam que, na criação e na manutenção da convivialidade, da vida íntima, parte integrante é lidar com situações que a ameaçam, como a guerra, a doença e a morte. As habilidades para se viver em uma íntima convivialidade são ensinadas às crianças e aos jovens.

Algo semelhante acontece na vida cotidiana dos Sanöma. A guerra, analisada como idioma central nos Yanomami por muitos autores (Albert 1989, 1990), está voltada para o exterior; o interior da vida social, por sua vez, deve ser manejado de tal forma que a guerra não o domine. Espera-se que as pessoas sejam generosas e saibam rir de si mesmas. Quando alguém se encontra taciturno, é dado um tempo para que se restabeleça; está tiko de (outro), isso deve ser momentâneo; a raiva ou qualquer outro sentimento sem ser o afeto, o cuidado, deve ser dissipado. A insatisfação contínua é sinal para se buscar outro local de moradia, em uma comunidade distante, pois há possibilidades de escolha. A pessoa tem autonomia para partir.

Os Sanöma contam que a raiva excessiva de um sogro com relação ao genro o fez esfregar tanto as pernas com um osso que acabou transformando-se em um animal, o veado, com suas pernas finas, o qual saiu correndo para a floresta. A melhor forma de ser um guerreiro Sanöma é sabendo controlar sua raiva e direcioná-la para outros grupos distantes da sua comunidade. O guerreiro dever rir e ser generoso. A raiva e a vingança surgem da dor da morte de um parente próximo, como afirmou Alès (2000), e é direcionada para outros subgrupos. Assim, transitam em um contínuo entre amor e raiva, direcionando esses sentimentos a pessoas e coletivos determinados. Dessa mesma maneira, entre os Sanöma, no interior do grupo, o amor e o cuidado com os próximos são elementos centrais que podem desencadear a raiva e a vontade de vingança quando a morte se faz presente entre parentes próximos.

As interações com grupos distintos ${ }^{4}$ são constantes na vida cerimonial Sanöma, mas há algo delicado nessa vida que é saber "manejar o cotidiano", nos termos de Overing (1999). No caso dos Sanöma, isso significa não deixar o guerreiro se contrapor ao seu coletivo, ou deixar

4 No multiverso Sanöma, eles se relacionam com outros grupos indígenas (subgrupos Yanomami, Yecuana, Macuxi etc., e diversos segmentos dos não indígenas), ao mesmo tempo que lidam com o mundo das queixadas, dos sai töpö, criaturas com corpos diversificados que habitam a floresta, têm suas famílias. Eles devem, portanto, ter cuidado para se relacionar com esses entes. Também há os mortos, que configuram outro coletivo/grupo, e vivem em uma aldeia distante. Os sapuli são os grandes diplomatas desse multiverso. 
que uma pessoa se transfigure em uma criatura não Sanöma. Nesse sentido, as mulheres Sanöma estão a todo momento "manejando a vida", por meio da produção de alimentos, promovendo a consubstancialidade, aproximando corpos e substâncias, afastando corporalidades inimigas que podem se voltar contra elas e seu grupo. São elas que cuidam dos guerreiros quando retornam e devem fazer um ritual kanenemo, para retirar o sangue e a gordura dos inimigos mortos, que impregnam os matadores. São elas que cuidam dos corpos da/o jovem no ritual de iniciação, alimentando-a/o e limpando-a/o nesse processo transformativo, especialmente da jovem que deve aprender a lidar com a potência do sangue feminino. São elas que levam o chibé, feito por elas - e, portanto, detém a corporalidade delas ${ }^{5}$ -, para os estrangeiros se alimentarem, quando adentram o território (esse é o primeiro alimento ofertado e que aciona o processo inicial de consubstancialidade). São elas que produzem o leite materno e o alimento da criança ao longo de sua vida. Após ser feita pelo esperma do pai na gestação, a criança deve ser fabricada com partes de corporalidade da mãe, que estão no leite materno e no alimento feito por suas mãos, as quais deixam marcas do seu corpo. A criança é feita de corpos, sentidos e pensamentos sobre como é ser Sanöma e de partes dispersas como o duplo animal, as marcas das pegadas, a sombra, os nomes. Esses corpos são genderizados, acabarão por deter as agências masculinas e femininas. Essa corporalidade Sanöma está vinculada a um modo de viver e sentir.

Na sociocosmologia Sanöma, o corpo deixa marcas, as quais estão nos alimentos das roças, nas próprias roças manejadas, nas casas construídas, nos instrumentos usados pela pessoa, nos alimentos coletados na floresta e nos rios, bem como nos alimentos cozidos. Nesse processo, as mulheres fabricam territórios, pessoas e histórias, assim como os homens, no entanto, cada um deve dominar habilidades e agências requeridas por corpos genderizados. Essa dinâmica se aproxima do que ocorre com os Matses, como afirma Matos (2018:118): a construção da pessoa (homem ou mulher) se faz em um duplo movimento do "[...] aparentamento com parentes, e do aparentamento (consubstancialização) com outros, sujeitos extrassociais [vegetais e animais] [...]”. No caso da pessoa Sanöma, esses se fazem em corpos genderizados na interação entre diversos seres, que

$5 \mathrm{Na}$ teoria Sanöma, corporalidade não está restrita ao corpo em si, mas as pessoas deixam suas marcas (partes de sua corporalidade) no que fazem, onde vivem e nas atividades que realizam. Assim, ao produzirem o alimento com suas mãos ou cultivarem plantas em suas roças, elas deixam marcas dos seus corpos, parte dos seus corpos, nesses alimentos e cultivos. 
se efetivam tanto no interior da comunidade quanto no exterior, ou melhor, essa fronteira entre interior e exterior acaba por ser borrada ou maleável, pois o movimento de consubstancialização e alteração dos sujeitos faz com que ela se expanda ou retraia. $\mathrm{Na}$ vida cotidiana, as mulheres detêm os mecanismos de promover a consubtancialização; o alimento é central nesse processo. Por sua vez, os xamãs controlam os mecanismos dessa consubstancialização fora do parentesco, viajam para o território de um sai töpö, se casam, passam a conhecer e, consequentemente, a controlar as forças dessas criaturas. Acabam por promover a consubstancialização no cotidiano de outros mundos.

O poder transformacional dado a algumas substâncias produzidas pelas mulheres, como sangue e alimento, tem ressonância com o sangue e a gordura do inimigo, produzidos no guerreiro após o ataque ao inimigo/outro, assim como com as cinzas do/produzidas pelo morto, que devem ser ingeridas pelos parentes próximos. A socialidade Sanöma depende da negociação em manter a guerra fora da vida comunitária e, ao mesmo tempo, ter o guerreiro e o xamã ativos para vingar alguma morte. Para qualquer adoecimento ou morte na comunidade, o xamã lança sua vingança para um grupo distante. Ao mesmo tempo, por meio da comensalidade, as mulheres aproximam os estrangeiros, fazem parentes e cuidam da ameaça do outro na vida cotidiana.

A agência feminina se articula especialmente na criação de filhas/os e de outros/as que compõem a família extensa, na produção de alimentos, no cultivo e na coleta em floresta/roças/rios.

\section{INTERPRETAÇÕES SANÖMA SOBRE INFORMAÇÕES CIENTÍFICAS/ESTATAIS: AMPLIANDO POSSIBILIDADES}

Nesta seção, analiso como dados científicos do campo epidemiológico apresentam a desnutrição infantil dos Sanöma e como os Yanomami são lidos, entre os povos indígenas, como os mais baixos e com mais baixo peso da América do Sul, o que tem sido associado à desnutrição infantil (Orellana et al. 2019). Cabe enfatizar que o levantamento de dados sobre a desnutrição infantil entre os Sanöma acontece em um contexto onde este povo vive principalmente do seu sistema agrícola (roça, coleta, pesca e caça). As questões que esses dados levantam são: há algum problema nos alimentos dos Sanöma ou há algum problema com essas pesquisas sobre desnutrição infantil? Ao mesmo tempo, trago a discussão das mulheres Sanöma e sobre como elas estão enfrentando essa situação.

Para explicar esse cenário da desnutrição e de baixa estatura dos Yanomami, as informações transitam entre fatores genéticos (Holmes 1995) 
ou ambientais, como adoecimentos, acesso e disponibilidade de alimentos e acesso a serviços (Orellana et al. 2019). Essas análises relacionam a baixa estatura e o baixo peso com maiores taxas de hospitalização, mortes por doenças infecciosas, menor nível de escolaridade, menor renda, bem como menor desempenho em testes de quociente de inteligência (QI). E todo esse argumento dos dados epidemiológicos levantados informa sobre a desnutrição infantil. A questão é: como a vida Yanomami pode ser lida desta maneira, esses elementos trazidos pelos dados epidemiológicos, que associam e criam uma análise causal entre baixa estatura, baixo peso e desnutrição infantil, formam uma análise acabada? Para alguns pesquisadores, sim, mas, aqui, apontamos a compreensão de que, para os Sanöma, não.

Pantoja (2012) analisou o estado nutricional de crianças menores de cinco anos de idade e que pertencem ao DSEI Yanomami, no período de maio de 2008 a abril de 2009, com base nos dados do Sistema de Vigilância Alimentar e Nutricional (SISVAN) Indígena. De acordo com a autora, entre os Yanomami, no ano de 2010, a taxa de mortalidade infantil (TMI) chegou a 120,95 óbitos por cada mil nascidos vivos (Pantoja 2012:26). A média nacional é de 19 óbitos por mil nascidos vivos, em 2009, de acordo com o Instituto Brasileiro de Geografia e Estatística
(IBGE). No polo-base de Auaris, onde os Sanöma se encontram, a autora analisou a prevalência de déficit de estatura/idade (E/I) superior a $81 \%$ das crianças em todos os períodos e em todas as faixas etárias (variação de 81,6 a 88,3\%). Em alguns períodos (maio a julho de 2008 e fevereiro a abril de 2009), nas faixas etárias de 24 a 35 e de 36 a 59 meses, verificou-se média de prevalência de déficit nutricional superior a $90 \%$ em relação às crianças. No caso do indicador de peso/idade (P/I), mais de $50 \%$ das crianças apresentaram baixo peso (variação de 55,5 a 61,8\%). Com exceção das faixas etárias de 0 a 5 e de 6 a 12 meses, todas as demais apresentaram valores de baixo peso superiores a 55\%. Em relação ao baixo peso/estatura $(\mathrm{P} / \mathrm{E})$, a autora observou prevalências superiores a 4,5\% (variação de 4,6 a 9,3\%). A faixa etária de 12 a 23 meses de idade foi a que apresentou maior prevalência em todos os períodos (variação de 9,7 a 16,8\%). De acordo com Horta et al. (2013), o estado nutricional deve ser analisado em um contexto mais amplo, sendo necessário enfatizar a relevância social, econômica, ambiental em diferentes escalas (local, regional e nacional).

Essas informações referentes a uma perspectiva exclusivamente biológica (da ciência médica) sobre a estatura, o peso e o estado nutricional dos Sanöma somaram-se com a visita das técnicas da SESAI e da UNICEF, que relataram o seguinte 
cenário: crianças de um até os cinco anos, que já estão andando, ficam em casa comendo somente chibé, não almoçam, enquanto os adultos não se encontram nas casas. Esse período na infância é crítico para a SESAI, pois essas crianças são as que não estão mais no colo da mãe, acompanhando-a por todos os lugares, e ficam nas proximidades das casas com mulheres e homens mais velhos, bem como com crianças mais velhas e adolescentes, os quais são pessoas que dividem o cuidado com as mães. Esse cenário era visto como problemático para a SESAI. Vale enfatizar, aqui, que a concepção de família extensa não é percebida em sua potência cuidadora pelos técnicos do governo, que também não compreendem o regime alimentar, de comer duas refeições ao dia, uma no início da manhã e outra pela noite, pois ao longo do dia os adultos estão embrenhados na floresta, nas roças, nas trilhas e nos igarapés, coletando e caçando. Ao longo do dia, as crianças estão fazendo pequenas refeições, assim como os adultos.

Portanto, ao adentrarmos a vida dos Sanöma, é possível perceber que estão localizados em um amplo território, onde plantam pequenas roças diversificadas, fazem uso da floresta, de suas plantas, de cogumelos, insetos, méis, pequenos peixes e crustáceos, e que também caçam animais. Homens e mulheres transitam, produzem roças de dimensões menores do que os Yekuana, vizinhos falantes de uma língua Caribe, conhecidos por suas grandes roças de maniva, onde produzem farinha para venda, contando com o auxílio de muitos instrumentos não indígenas para produção. As comparações entre esses modos de produção Sanöma e Yekuana são uma constante e acabam por ser mais um julgamento negativo sobre as práticas de cultivo e alimentares dos Sanöma.

Reagindo a esses modos de compreensão da SESAI, há outro movimento, o qual não quero acreditar que seja uma coincidência: as mulheres estão atuando em frentes onde nunca as tinha visto. Elas são conselheiras de saúde, tuxauas, e há uma agente indígena de saúde. Essas novas posições de diálogo com os não indígenas eram dominadas pelos homens que falavam português e que se situavam na posição desejada por uma leitura de gênero ocidental, a qual confere como hierarquicamente superior a agência masculina. Dessa maneira, servidores do Estado conversam somente com eles e se interessam apenas por ouvi-los. Agora, mesmo sem saber português, elas estão na linha de frente, falam para os não indígenas por meio de tradutores indígenas, homens Sanöma. Apresentam uma fala dura, mandam os homens se calarem, pois elas dominam o cenário do problema que está sendo abordado (tungíase e desnutrição infantil). Assim elas se defendem e demandam ações por parte da SESAI, apresentando outra realidade, outras preocupações. Vale enfatizar que a SESAI 
também apresentou uma nova demanda para que houvesse a presença de conselheiras indígenas e de agentes indígenas de saúde. Atualmente, essas conselheiras e lideranças femininas falam quando o assunto lhes diz respeito.

Não quero negar os vários adoecimentos que acometem os Yanomami, mas a realidade científica construída pode estar baseada em pressupostos perigosos, escamoteando dimensões mais importantes. Por exemplo, enfatizar que o fogo doméstico causa os problemas respiratórios nas crianças, e não vírus e bactérias que chegam a Auaris, é base para construções de intervenções avassaladoras. Isso significa trazer o problema para o modo de vida dos Sanöma, para a maneira como se organizam em suas casas, como as constroem e como produzem alimentos, e retirar o problema do serviço de saúde e da disponibilização de terapêuticas que devem ser ofertadas pelo Estado.

O polo-base de Auaris é um ponto de confluência, contando com a presença do $5^{\circ}$ batalhão do Exército, de profissionais de saúde, de pista de pouso, sendo, assim, um local de trânsito, onde pessoas são especialmente deslocadas por motivos de adoecimento, o que pode configurá-lo como um local de trânsito também desses agentes patogênicos. Para os Sanöma, essa presença intensa de estrangeiros está claramente associada aos adoecimentos que os acometem, pois há facilidade em ver partes de suas corporalidades agredidas. Além disso, há uma discussão no meio científico - relatada por técnicos da SESAI - quanto à existência de um corredor na floresta por onde insetos transmissores de doenças circulariam, o que seria uma explicação para os altos índices de malária na epidemia da década de 1990, em Auaris, local onde não se viveu a presença intensa de garimpeiros, como em outras partes da Terra Indígena Yanomami, mas que apresentou índices alarmantes de adoecimento por malária. Essa explicação do corredor por onde agentes patogênicos circulam se assemelha aos caminhos por onde eram lançados venenos ( $w a z u$ ), relatados pelos sapuli (xamãs). Esses envenenamentos aconteceram há muito tempo, provocaram muitas mortes entre os seus. Grupos inimigos emitiram pelo ar o wazu (veneno), que seguia trilhas na floresta e nos leitos dos rios. Os estudos que revelam desnutrição infantil e baixa estatura também incomodam os Sanöma, por isso eles querem fazer um mapeamento de seu sistema alimentar, a fim de estabelecer diálogos com a SESAI, sendo esse o principal objetivo do projeto que estamos fazendo em conjunto.

A partir das inquietações das mulheres Sanöma e de seu reposicionamento político com relação aos não indígenas, reconheço, nesse movimento, uma tentativa de capturar ou avançar sobre a 
ciência ocidental, e de não deixar a narrativa sobre os temas tratados pela ciência ocidental somente com ela. Se o espaço da ciência participa da produção de realidades, que desencadeiam práticas e intervenções, então, essas mulheres estão dispostas a agir sobre essas realidades.

Assim, inspiro-me em Mol (2002) e sigo sua sugestão de que: "[...] knowledge is no longer treated primarily as referential, as a set of statement about reality, but is a practice that interferes with other pratices. It therefore participates in reality. And various other shifts follow from this" (Mol 2002:152-153). Dessa forma, produzindo os fatos e participando deles, como o faz a ciência ocidental, as mulheres Sanöma constroem um terreno cosmopolítico, também produzindo conhecimento e realidade, afrontando a realidade criada pela ciência ocidental.

Resultado dessa cosmopolítica está também refletido no projeto de pesquisa construído em conjunto com a associação indígena Sanöma Ibasali, tendo em vista que:

\footnotetext{
Day-to-day reality, the life we live, is also a fleshy affair. A matter of chairs and tables, food and air, machines and blood. Of bodies. That is a good reason not to leave these issues in the hands of medical professionals alone but to seek ways, lay ways so to speak, to freely talk about them (Mol 2002:27).
}

Essas mulheres estão mobilizadas para não deixar os argumentos somente nas mãos dos profissionais e gestores estatais. Dessa maneira, elas criam suas narrativas e confrontam realidades. Esse terreno é o da cosmopolítica Sanöma, onde elementos como pesos e medidas, corporalidades, alimentos, sistemas agrícolas passam a ser atravessados por outras realidades. Esses elementos que marcam a interpretação de agentes da SESAI são, agora, usados pelas mulheres Sanöma, referindo-se à realidade dessas e questionando o que é produzido pelos agentes do órgão. Fazer uso desses elementos como pesos, medidas e alimentos é como "trazer a público um ingrediente que tanto pertence ao território quanto se conecta com um exterior contra o qual este território se protege" (Stengers 2008:42).

Não sendo coincidência, essas mulheres trouxeram as falas mais fortes na reunião que acompanhei, a fala tradicional Sanöma, onde apresentam os problemas que enfrentam. Nunca as vi entrarem em cena dessa maneira nas reuniões de interação com os não indígenas. Agora, eram conselheiras de saúde, três falaram na reunião, conjuntamente com outros três conselheiros e outras duas lideranças.

Nessa reunião, elas colocaram suas demandas à SESAI: falaram sobre a instalação de torneiras na comunidade; o cuidado com suas casas (perguntavam se uma opção seria ter chão de cimento); o uso de ferramentas para cultivo e 
produção de alimentos (perguntavam se a SESAI poderia fornecer machados, motosserras, raladores de mandioca elétricos); sobre ter animais coloridos para criar (perguntavam se uma opção seria ter girafas, elefantes e rinocerontes...). Um dos homens conselheiros falou que eles tinham os dentes pretos, tão questionados pelos técnicos não indígenas, porque eram irmãos dos macacos e não porque estavam com cárie ou com os dentes doentes devido ao consumo de alimentos dos não indígenas. Várias dessas falas foram intermediadas por comentários, risadas e momentos de seriedade.

Assim, essas mulheres traziam mais que urgência de atuação sobre essa realidade criada, elas sabiam que estavam apresentando propostas inviáveis, mas reconhecidas pelos agentes da SESAI. Configurava-se o espaço de proposição cosmopolítica. Nos termos de Stengers (2018), tratavam de desacelerar os outros, resistirem à maneira como a situação era apresentada, cujas urgências mobilizavam o pensamento-ação. E resistiam não porque a apresentação seja falsa, não porque as urgências sejam mentirosas, mas porque "há algo de mais importante" (Stengers 2018). Criavam um espaço de hesitação sobre questões, ameaças e problemas. Eram os "seus" saberes, os fatos produzidos por "suas" técnicas, mas igualmente os julgamentos associados às "suas" práticas que estavam na linha de frente. E elas estavam presentes, revelando o que existia ou estava em jogo e era mais importante.

As mulheres Sanöma não situam seus saberes particulares, como parte da ciência ocidental, ocupando um mesmo cosmos englobante. $\mathrm{Na}$ cosmopolítica, não há a proposta de saberes articulados, mas acontecimentos que questionam a maneira como razões são construídas.

Os Sanöma estão inserindo uma discussão sobre corpos e alimentos. Eles têm, na memória, o momento em que começaram a cultivar, a ter as roças; por conseguinte, são feitos de corpos que se alimentam, transitam, reagem, sentem de maneira particular e se produzem também de maneira particular em meio à floresta. Eles afirmam que, antes de conhecerem as roças, que thes foram apresentadas por um antepassadocobra, viviam sempre na prática do hinamo kule(realizar expedições de caça onde se pernoita), isto é, transitando pela floresta, fazendo acampamentos temporários, caçando e coletando. Hoje, realizam o hinamo kule somente naépoca da seca, entre outubro e março, quando a família extensa realiza acampamentos na floresta, para caçar e coletar outros alimentos. Atualmente, produzem uma roça muito particular (de pequenas dimensões de manivas e bananas principalmente, aliadas a outros cultivos); têm um regime alimentar que foca nas alimentações em conjunto, quando acordam e quando vão dormir, não almoçando como os não indígenas. Ao longo do dia, estão embrenhados 
na floresta, produzindo e se relacionando. Os corpos seguem um ciclo de vida particular, que transita entre ser gordo-magro (seco-denso), o que é manejado por meio de várias tecnologias. Essa realidadeé importante e as mulheres Sanöma estão sendo protagonistas na criação desse terreno cosmopolítico, de enfrentamento e hesitação na efetivação de uma realidade que lhes pode ser avassaladora.

\section{FINALIZANDO: CRIANDO REALIDADES}

A agência feminina Sanöma afronta o contexto interétnico vigente até então, quando os homens dominavam a fala e elas não se importavam. Hoje, diante das acusações sobre o descuido com as suas crianças, essas mulheres tomam a cena. Mesmo sem dominar o português, elas estão na linha de frente. Explicam que são elas que diversificam a alimentação - a roça de maniva é aberta pelos homens, que as auxiliam quando plantam, mas são elas que inserem os outros alimentos, diversificando-a. Afirmam que o mais valorizado é a carne de caça. Os Sanöma usam uma palavra específica para fome de caça (naki). Eles relembram o período quando os antepassados viviam em acampamentos transitórios na floresta, quando viviam da caça realizada pelos homens e da coleta realizada pelas mulheres na floresta e ao longo dos igarapés. Era um tempo de fartura. Depois, eles aprenderam como fazer a roça, as sementes lhes foram dadas pelo antepassado da cobra e foi o fim da era dos acampamentos que, hoje, são praticados somente na época da seca, quando passam meses fora da aldeia e das proximidades das roças. Em meio a gargalhadas, explicam que, caso os brancos queiram que eles comam mais, devem trazer seus animais coloridos (girafas, rinocerontes, zebras). Apresentam suas demandas por torneiras nas comunidades, para facilitar a coleta de água. E sabem das diferenças dos regimes alimentares deles com relação aos brancos, que comem três refeições ao dia, intercaladas por pequenos lanches. Essas mulheres dividem o trabalho da produção alimentar com os homens, elas estão na roça, na produção do beiju, derivado da maniva, na coleta realizada na floresta e nos igarapés, enquanto eles caçam e pescam. Elas cuidam de seus/suas filhos/ as da família extensa, formada por avós, pai, mãe, suas filhas, genros e netos/as. Cuidam da limpeza das casas e se aborrecem diante de argumentos de que não possuem higiene com suas casas, nem com seus filhos. Nas reuniões, por meio das "falas fortes", elas desestabilizam a realidade criada pelo branco e a questionam, afrontam, com soluções, que os brancos supõem ser desconhecimento ou ignorância, achando que elas não sabem o que falam. Seguem limitando a realidade criada pela ciência ocidental, tencionando-a e questionando-a. Elas recusam a redução do debate sobre seus regimes alimentares a universais definidos pelos brancos. 


\section{REFERÊNCIAS}

Albert, B. 1989. Yanomami 'violence': inclusive fitness or ethnographer's representation? Current Anthropology 30(5):637-640. DOI: http://dx.doi.org/10.1086/203793.

Albert, B. 1990. On Yanomami Warfare: a rejoiner. Current Anthropology 31:558-563.

Albert, B. 2014. Situação etnográfica e movimentos étnicos. Notas sobre o trabalho de campo pósmalinowskiano. Campos 15(1):129-144.

Alès, C. 2000. Anger as a maker of love. The ethic of conviviality among the Yanomami, in Anthropology of love and anger. The aesthetics of conviality in native South America. Editado por J. Overing e A. Passes, pp. 133-151. New York/London: Routledge.

Belaunde, L. E. 2001. Viviendo bien: género y fertilidad entre los Airo Pai de La Amazonia Peruana. Lima: CAAAP.

Benites, S. 2018. Viver na língua Guarani Nhandeva (mulher falando). Dissertação de Mestrado, Museu Nacional, Universidade Federal do Rio de Janeiro, Departamento de Antropologia Social, Rio de Janeiro.

Evangelista, R., e M. Ricarte. 2017. A ação do exército brasileiro na Terra Indígena Yanoami frente à atenção básica de saúde e aos indígenas Sanöma na região de Auaris. Working Papers - Fronteira Política 1:WP03.

Fundação Oswaldo Cruz (Fiocruz). 2009. I Inquérito Nacional de Saúde e Nutrição dos Povos Indígenas. Relatório Final, RJ.

Guimarães, S. 2005. Cosmologia Sanumá: o xamã e a constituição do ser. Tese de Doutorado, Universidade de Brasília, Departamento de Antropologia, Brasília. 
Holmes, R. 1995. Small is adaptive: nutritional anthropometry of native Amazonians, in Indigenous peoples and the future of Amazonia. Editado por L. E. Sponsel, pp. 121-148. Tucson: University of Arizona Press.

Horta, B., R. Santos, J. Welch, A. Cardoso, e J. Santos. 2013. Nutritional status of indigenous children: findings from the First National Survey of Indigenous People's Health and Nutrition in Brazil. International fournal for Equity in Health 12:23. DOI: http://dx.doi.org/10.1186/1475-9276-12-23.

Instituto Socioambiental (ISA). 2019. Povos Indígenas no Brasil. Disponível em: https://pib.socioambiental. org/pt/P\%C3\%A1gina_principal. Acesso em: jul. 2019.

Lugones, M. 2014. Rumo a um feminismo descolonial. Revista de Estudos Feministas 22(3):935-952.

Marinho, G., G. Borges, E. Paz, e R. Santos, 2019. Mortalidade infantil de indígenas e não indígenas nas microrregiões do Brasil. Revista Brasileira Enfermagem 72(1):57-63. DOI: http://dx.doi.org/10.1590/00347167-2017-0646.

Matos, B. A. 2018. Povo onça, povo larva: animais e plantas na constituição da pessoa, diferenciação de gênero e parentesco matses. Revista de Antropologia 61(3):109-129. DOI: https://doi.org/10.11606/21790892.ra.2018.152038.

McCallum, C. 2001. How real people are made. Gender and sociality in Amazonia. Oxford: Berg.

Migliazza, E. 1967. Grupos linguísticos do território federal de Roraima, in Atas do Simpósio sôbre a Biota Amazônica. Editado por Herman Lent, pp. 153-173. V. II (Antropologia). Rio de Janeiro: Conselho Nacional de Pesquisas.

Migliazza, E. 1972. Yanomama grammar and intelligibility. Tese de Doutorado, Indiana University, Ann Arbor. 
Mol, A. 2002. The body multiple: ontology in medical practice. Durham/Londres: Duke University Press.

Orellana, J., L. Marrero, C. Alves, C. Ruiz, S. Hacon, M. Oliveira, e P. Basta, 2019. Associação de baixa estatura severa em crianças indígenas Yanomami com baixa estatura materna: indícios de transmissão intergeracional. Ciência \& Saúde Coletiva 24(5):1875-1883. DOI: http://dx.doi.org/10.1590/141381232018245.17062017.

Overing, J. 1986. Men control women? The "catch 22" in the analyses of gender. International fournal of Moral and Social Studies 1(2):135-156.

Overing, J. 1991. A estética da produção: o senso de comunidade entre os Cubeo e os Piaroa. Revista de Antropologia (34):7-33.

Overing, J. 1999. Elogio do cotidiano: a confiança e a arte da vida social em uma comunidade amazônica. Mana 5(1):81-107. DOI: http://dx.doi.org/10.1590/S0104-93131999000100004.

Overing, J. 2004. A reação contra a descolonização da intelectualidade. ILHA 6(1-2):5-27.

Overing, J., e A. Passes. 2000. Introduction: conviviality and the opening up of Amazonian anthropology, in The anthropology of love and anger: the aesthetics of conviviality in Native Amazonia. Editado por J. Overing e A. Passes, pp. 1-30. London/New York: Routledge.

Pantoja, L. 2012. Estado nutricional de crianças indígenas menores de cinco anos do DSEI Yanomami, Roraima, Brasil. Dissertação de Mestrado, Departamento de Epidemiologia em Saúde Pública, Escola Nacional de Saúde Pública Sérgio Arouca, Rio de Janeiro.

Ramos, A. 1990. Memórias Sanumá: espaço e tempo em uma sociedade Yanomami. São Paulo/Brasília: Editora Marco Zero/Editora UnB. 
Secretaria Especial de Saúde Indígena (SESAI). 2019. Distrito Sanitário Yanomami. Disponível em: www.saude.gov.br/sesai. Acesso em: jul. 2019.

Segato, R. 2012. Gênero e colonialidade: em busca de chaves de leitura e de um vocabulário estratégico descolonial. E-Cadernos CES 48:106-131. DOI: https://doi.org/10.4000/eces.1533.

Sociedade Brasileira de Dermatologia (SBD). 2017. Tungíase. Disponível em: https://www.sbd.org.br/ dermatologia/pele/doencas-e-problemas/tungiase/35/. Acesso em: jul. 2019.

Stengers, I. 2008. Experimenting with refrains: subjectivity and the challenge of escapingmodern dualism. Subjectivity 22(1):38-59. DOI: https://doi.org/10.1057/sub.2008.6.

Stengers, I. 2018. A proposição cosmopolítica. Revista do Instituto de Estudos Brasileiros (69):442-464. DOI: https://doi.org/10.11606/issn.2316-901X.v0i69p442-464.

Taylor, K. I. 1996. A geografia dos espíritos: o xamanismo entre os Yanomami setentrionais, in Xamanismo no Brasil: novas perspectivas. Organizado por J. M. Langdon, pp. 118-151. Florianópolis: Ed. da UFSC.

Veron, V. 2018. Tekombo'e Kunhakoty: modo de viver da mulher Kaiowá. Dissertação de Mestrado, Universidade de Brasília, Departamento de Sustentabilidade junto a Povos e Territórios Tradicionais, Brasília.

Victora, C. G., E. M. L. Aquino, M. C. Leal, C. A. Monteiro, F. C. Barros, e C. L. Szwarcwald. 2011. Maternal and child health in Brazil: progress and challenges. Lancet 377(9780):1863-1876. DOI: https://doi.org/10.1016/S0140-6736(11)60138-4.

Viveiros de Castro, E. 2012. "Transformação" na Antropologia, transformação da "Antropologia". Mana 18(1):151-171. DOI: http://dx.doi.org/10.1590/S0104-93132012000100006. 